\title{
PENGARUH LATIHAN PERNAPASAN BUTEYKO TERHADAP ARUS PUNCAK EKSPIRASI (APE) PADA PENDERITA ASMA
}

\author{
Oleh: Dandy Prastyanto dan Wara Kushartanti \\ Jurusan Pendidikan Kesehatan dan Rekreasi FIK UNY
}

\section{Abstrak}

Latar belakang dilaksanakannya penelitian ini adalah banyaknya penderita asma berdasarkan prevalensi asma di Indonesia. DI Yogyakarta menempati posisi ketiga terbanyak dan pada usia 15-24 tahun menempati posisi kedua terbanyak penderita asma. Penelitian ini bertujuan untuk mengetahui pengaruh latihan pernapasan buteyko terhadap Arus Puncak Ekspirasi (APE) pada penderita asma mahasiswa Universitas Negeri Yogyakarta.

Penelitian ini merupakan penelitian pre-eksperimen dengan desain penelitian pretest and posttest. Subjek penelitian ini adalah mahasiswa Universitas Negeri Yogyakarta yang menderita asma. Sampel dalam penelitian ini adalah mahasiswa yang menderita asma berjumlah 12 orang. Subjek diberikan perlakuan dengan metode latihan pernapasan buteyko, perlakuan (treatment) dilakukan 3 kali sehari (pagi, siang, malam) selama 4 minggu pertemuan, kemudian sebelum dan sesudah perlakuan dilakukan tes APE dengan satuan liter/menit ( $1 / \mathrm{min})$. Instrumen pengambilan data menggunakan tes peak flow meter. Teknik analisis data menggunakan uji-t, setelah sebelumnya dilakukan uji normalitas dan uji homogenitas.

Hasil penelitian menunjukkan bahwa ada pengaruh yang signifikan latihan pernapasan buteyko terhadap APE dengan $\mathrm{p}$ value $0,000<0,05$. Rerata kenaikan APE setelah mendapatkan perlakuan dengan latihan pernapasan buteyko sebesar 89,17 1/min. Dengan demikian dapat disimpulkan bahwa latihan pernapasan buteyko dapat meningkatkan APE pada penderita asma.

KataKkunci: asma, latihan pernapasan buteyko, arus puncak ekspirasi

Kesehatan merupakan sesuatu yang sangat penting bagi kehidupan manusia, akan tetapi di era globalisasi ini masalah kesehatan semakin banyak. Di Indonesia pemerintah sudah berupaya dalam pembangunan kesehatan seperti yang dijelaskan dalam Rencana Strategi Departermen kesehatan (Resentra Depkes) tahun 2005-2009 disebutkan bahwa pembangunan kesehatan di Indonesia dalam tiga dekade ini yang dilaksanakan secara berkesinambungan telah cukup berhasil meningkatkan derajat kesehatan. Meskipun demikian, derajat kesehatan di Indonesia masih terhitung rendah apabila dibandingkan dengan negara-negara tetangga. Memasuki milenium ketiga, Indonesia menghadapi berbagai perubahan dan tantangan strategis yang mendasar baik internal maupun eksternal yang perlu dipertimbangkan dalam melaksanakan pembangunan Nasional termasuk pembangunan kesehatan (Depkes, 2005 dalam Wiku Adisasmito, 2010: 5). 
Masalah kesehatan yang menjadi sorotan di Indonesia yaitu masalah penanganan penyakit. Penyakit yang berkembang di Indonesia sangat pesat selain penyakit menular yang selalu menjadi masalah, penyakit tidak menular juga semakin meningkat selaras dengan hasil riset Kesehatan dasar (Riskesdas) tahun 2007 "Masalah kesehatan masyarakat yang sedang kita hadapi saat ini dalam pembangunan kesehatan adalah beban ganda penyakit, yaitu disatu pihak masih banyaknya penyakit infeksi yang harus ditangani, dilain pihak semakin meningkatnya penyakit tidak menular. Sedangkan menurut Ekowati Rahajeng 2011: 23 proporsi angka kematian penyakit tidak menular meningkat dari 41,7\% pada tahun 1995 menjadi 59,5\% pada tahun 2007 salah satunya yaitu asma".

Penyakit asma termasuk lima besar penyebab kematian di dunia. Sementara di Indonesia, penyakit ini masuk dalam sepuluh besar penyebab kesakitan dan kematian (Siswono, 2007 dalam Suharmiati, dkk, 2010: 395). Hal ini tentunya akan menggangu produktivitas dan aktivitas belajar sehari-hari. Prevalensi yang tinggi menunjukkan bahwa pengelolaan asma belum berhasil. Berbagai faktor menjadi sebab dari keadaan yaitu berbagai kekurangan dalam hal pengetahuan tentang asma, melakukan evaluasi setelah terapi, sistimatika dan pelaksanaan pengelolaan, dan upaya pencegahan dan penyuluhan dalam pengelolaan asma. Mengingat hal tersebut, pengelolaan asma yang terbaik haruslah dilakukan sejak dini dengan berbagai tindakan pencegahan agar penderita tidak mengalami serangan asma (Sigit Nugroho, 2010:2).

Penilaian derajat asma dapat diketahui dengan monitoring arus puncak ekspirasi (APE). Monitoring APE penting untuk menilai berat asma, derajat variasi diurnal, respons pengobatan saat serangan akut, deteksi perburukan sebelum menjadi serius, respons pengobatan jangka panjang, dan identifikasi pencetus misalnya pajanan lingkungan. Pada penderita asma nilai APE berada pada nilai normal. Pemeriksaan APE mudah dan sederhana untuk menilai berat obstruksi jalan napas dengan menggunakan peakflow meter. Peakflow meter relatif murah dan dapat dibawa ke mana-mana, sehingga pemeriksaan itu tidak hanya dapat dilakukan di klinik, rumah sakit tetapi dapat dilakukan di rumah penderita secara mandiri, akan tetapi belum banyak penderita asma yang memahami dan menggunakannya (PDPI, 2006: 31).

Banyaknya penderita asma di Indonesia, tentunya membutuhkan suatu solusi agar penyakit asma bisa berkurang, selain dengan penanganan dokter, harus ada penanganan di luar itu yang berfungsi sebagai terapi untuk membantu mengurangi gejala asma. Terapi yang tepat agar dapat membantu dan mengurangi penderita asma di Indonesia, yaitu dengan terapi komplementer (non-farmakologis) salah satunya dapat dilakukan dengan olah teknik pernapasan. Dalam teknik ini diajarkan teknik mengatur napas apabila pasien mengalami asma. Salah satu metode yang dikembangkan untuk memperbaiki cara bernapas pada pasien asma 
adalah teknik olah napas, dapat berupa olahraga aerobik, senam, dan teknik pernapasan seperti thai chi, yoga, mahatma, buteyko dan pranayama (Fadhil, 2009). Buteyko digunakan untuk mengontrol gejala asma, banyak keunggulan dari buteyko seperti dapat dilakukan dimanapun dan kapanpun, dan mudah dilaksanakan.

Menurut Austin G, (2013:16) keunggulan dari latihan pernapasan buteyko yaitu, (1) mendorong pasien untuk bernapas sedikit, (2) melatih pola pernapasan pasien menggunakan serangkaian latihan pernapasan, (3) meningkatkan kontrol gejala asma dan kualitas hidup, (4) dapat digunakan bersama dengan obat konvensional, (5) dapat digunakan untuk orang dewasa dan anak-anak. Berdasarkan hasil pengamatan didapat bahwa di DI Yogyakarta dan pada usia 15-24 tahun terdapat banyak penderita asma. Oleh karena itu penulis tergerak untuk lebih meneliti tentang pengaruh latihan pernapasan buteyko terhadap arus puncak ekspirasi (APE) pada penderita asma mahasiswa Universitas Negeri Yogyakarta.

\section{KAJIAN PUSTAKA}

Asma

Asma (dalam bahasa Yunani ö $\sigma \theta \mu \alpha$, ásthma, "terengah") merupakan peradangan kronis yang umum terjadi pada saluran napas yang ditandai dengan gejala yang bervariasi dan berulang, penyumbatan saluran napas yang bersifat reversibel, dan spasmus bronkus. Gejala umum meliputi mengi, batuk, dada terasa berat, dan sesak napas. Penyakit Asma berasal dari kata "ashtma" yang diambil dari bahasa Yunani yang berarti "sukar bernapas".

Penyakit asma merupakan proses inflamasi kronik saluran pernapasan yang melibatkan banyak sel dan elemennya. Proses inflamasi kronik ini menyebabkan saluran pernapasan menjadi hiperesponsif, sehingga memudahkan terjadinya bronkokontriksi, edema, dan hipersekresi kelenjar, yang menghasilkan pembatasan aliran udara di saluran pernapasan dengan manifestasi klinik yang bersifat periodik berupa mengi, sesak napas, dada terasa berat, batuk-batuk terutama pada malam hari atau dini hari/subuh. Gejala ini berhubungan dengan luasnya inflamasi, yang derajatnya bervariasi dan bersifat reversibel secara spontan maupun dengan atau tanpa pengobatan (Global Initiative for Asthma, 2011 dalam Pusat Data dan Informasi Kementerian Kesehatan RI, 2014).

Asma adalah suatu kelainan berupa inflamasi (peradangan) kronik saluran napas yang menyebabkan hiperreaktivitas terhadap berbagai rangsangan yang ditandai dengan gejala episodik berulang berupa mengi, batuk, sesak napas dan rasa berat di dada terutama pada malam atau dini hari yang umumnya bersifat reversibel baik dengan atau tanpa pengobatan (Departemen Kesehatan RI, 2009: 7) 
Asma adalah kondisi peradangan kronis pada saluran pernapasan yang ditandai dengan mengi yang berulang, sesak napas, sesak dada dan batuk. Asma tidak dapat dicegah atau disembuhkan tetapi manifestasi klinis dapat dikendalikan secara efektif dengan pengobatan yang tepat. Ketika asma terkontrol, gejala hanya sesekali kambuh (GINA, 2012: 1). Asma merupakan penyakit yang kompleks yang dapat diakibatkan oleh faktor biokimia, endoktrin, infeksi, otonomik, dan psikologi. Asma bronkiale merupakan salah satu penyakit kronik dengan serangan intermiten. Serangan ditandai dengan adanya spasmus dari saluran bronkial, pembengkakan dinding bronkial dan banyaknya sekresi lendir. Semua keadaan tersebut mengakibatkan timbulnya batuk, bunyi ngik, sesak napas, dan rasa kontriksi pada dada (Wara Kushartanti, 2002 dalam Sigit Nugroho, 2009:3)

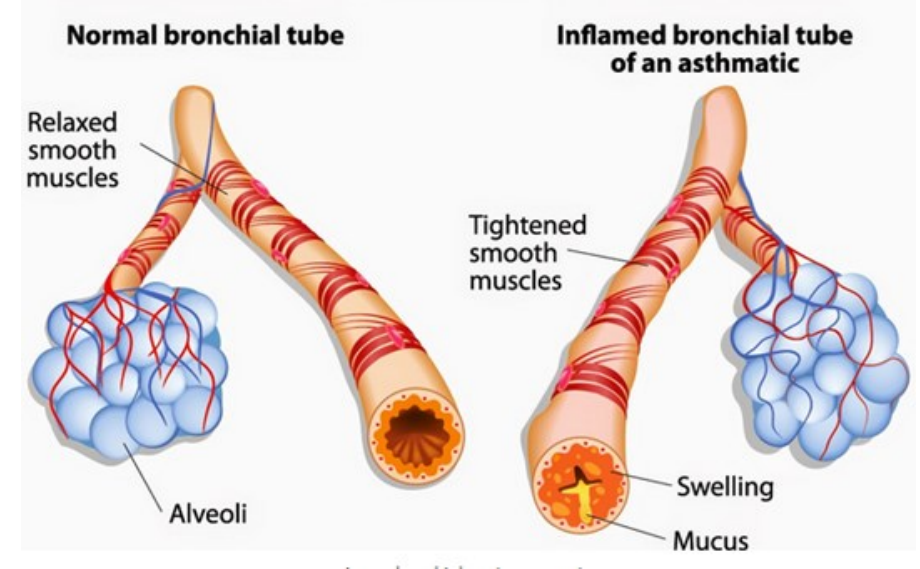

Gambar 3. Perbedaan Dinding Bronkial Normal dan Asma (sumber: http://www.duniainformasikesehatan.com)

Menurut Perhimpunan Dokter Paru Indonesia (2003: 6), asma merupakan gangguan inflamasi kronik saluran napas yang melibatkan banyak sel dan elemennya. Inflamasi kronik menyebabkan peningkatan hiperesponsif jalan napas yang menimbulkan gejala episodik berulang berupa mengi, sesak napas, dada terasa berat dan batuk-batuk terutama malam dan atau dini hari. Episodik tersebut berhubungan dengan obstruksi jalan napas yang luas, bervariasi dan seringkali bersifat reversibel dengan atau tanpa pengobatan.

Asma adalah kondisi kronis yang dapat menyebabkan gejala pernapasan tidak nyaman seperti mengi, sesak napas, batuk atau dada 'ketat' setiap hari. Selama eksaserbasi penyakit, semakin parah gejala dapat berkembang, membutuhkan terapi yang lebih intensif. Dalam proporsi kasus tersebut, masuk rumah sakit diperlukan dan dalam beberapa hasil yang fatal terjadi meskipun pengobatan terbaik. Asma dapat terjadi dalam menanggapi salah satu dari sejumlah pemicu, seperti alergen, infeksi, latihan, dan iritasi non-spesifik lainnya (Ministri of Health New Zealand, 2002: 13). Asma menyebabkan saluran udara menjadi lebih sensitif dan 
bereaksi terhadap hal-hal yang biasanya tidak bereaksi, seperti tungau udara atau debu dingin dan bahkan hewan peliharaa. Hal ini yang disebut pemicu (Asthma Society of Ireland, 2013: 2).

Asma merupakan penyakit yang tidak dapat disembuhkan tetapi dengan diagnosis, pengobatan dan edukasi pasien yang tepat dapat menghasilkan manajemen dan kontrol asma yang baik. Dengan terkontrolnya asma, dapat ditingkatkan kualitas hidup penderita asma (WHO, 2011). Jenis asma ini merupakan bentuk asma yang paling umum dan sering ditemukan. Asma ini mempunyai karakteristik dari bentuk alergi maupun bentuk idiopatik atau nonalergik, sedangkan klasifikasi asma berdasarkan tingkat keparahannya dapat dilihat pada Tabel 1.

Tabel 1. Klasifikasi Asma Berdasarkan Tingkat Keparahannya

\begin{tabular}{|c|c|c|}
\hline Derajat asma & Gejala & Fungsi Paru \\
\hline I. Intermiten & $\begin{array}{l}\text { Siang hari } \leq 2 \text { kali per minggu. } \\
\text { Malam hari } \leq 2 \text { kali per bulan. } \\
\text { Serangan singkat. } \\
\text { Tidak ada gejala antarserangan. } \\
\text { Intensitas serangan bervariasi. }\end{array}$ & $\begin{array}{l}\text { Variabilitas APE }<20 \% \text {. } \\
\text { VEP } 1 \geq 80 \% \text { nilai } \\
\text { prediksi. } \\
\text { APE } \geq 80 \% \text { nilai terbaik. }\end{array}$ \\
\hline II. Persisten Ringan & $\begin{array}{l}\text { Siang hari }>2 \text { kali per minggu, } \\
\text { tetapi }<1 \text { kali per hari. } \\
\text { Malam hari }>2 \text { kali per bulan. } \\
\text { Serangan dapat mempengaruhi } \\
\text { aktivitas. }\end{array}$ & $\begin{array}{l}\text { Variabilitas APE } 20- \\
30 \% \text {. } \\
\text { VEP } 1 \geq 80 \% \text { nilai } \\
\text { prediksi. } \\
\text { APE } \geq 80 \% \text { nilai terbaik. }\end{array}$ \\
\hline III. Persisten Sedang & $\begin{array}{l}\text { Siang hari ada gejala. } \\
\text { Malam hari }>1 \text { kali per minggu. } \\
\text { Serangan mempengaruhi aktivitas. } \\
\text { Serangan } \geq 2 \text { kali per minggul. } \\
\text { Serangan berlangsung berhari- } \\
\text { hari. } \\
\text { Sehari-hari menggunakan inhalasi. } \\
\beta 2 \text {-agonis short acting. }\end{array}$ & $\begin{array}{l}\text { Variabilitas APE }>30 \% \text {. } \\
\text { VEP1 } 60-80 \% \text { nilai } \\
\text { prediksi. } \\
\text { APE } 60-80 \% \text { nilai terbaik. }\end{array}$ \\
\hline IV. Persisten Berat & $\begin{array}{l}\text { Siang hari terus-menerus ada } \\
\text { gejala. } \\
\text { Setiap malam hari sering timbul } \\
\text { gejala. } \\
\text { Aktifitas fisik terbatas. } \\
\text { Sering timbul serangan. }\end{array}$ & $\begin{array}{l}\text { Variabilitas APE }>30 \% \text {. } \\
\text { VEP } 1 \leq 60 \% \text { nilai } \\
\text { prediksi. } \\
\text { APE } \leq 60 \% \text { nilai terbaik. }\end{array}$ \\
\hline
\end{tabular}

Sumber: (Persatuan Dokter Paru Indonesia. 2006)

\section{Latihan Pernapasan Buteyko}

Latihan pernapasan buteyko dikembangkan oleh Buteyko, seorang dokter Rusia yang mendalilkan bahwa asma disebabkan oleh hiperventilasi, kemudian mengusulkan bahwa semua manifestasi asma dapat dijelaskan atas dasar tegangan rendah karbondioksida. Teknik pernapasan buteyko dikembangkan untuk melatih penderita asma untuk mengurangi ventilasi 
mereka (Cowie, 2007: 1). Latihan pernapasan buteyko merupakan salah satu teknik olah napas yang bertujuan untuk menurunkan ventilasi alveolar terhadap hiperventilasi paru penderita asma (GINA, 2005).

Latihan pernapasan buteyko adalah terapi pernapasan yang unik yang menggunakan kontrol napas dan menahan nafas, latihan untuk mengobati berbagai kondisi kesehatan yang diyakini berhubungan dengan hiperventilasi dan rendahnya karbondioksida (Courtney, 2008: 59). Komponen utama dari buteyko yaitu terapi bernapas. Komponen pernapasan bertujuan untuk mengurangi hiperventilasi melalui pengendalian pengurangan napas, yang dikenal sebagai slow breathing dan reduce breathin, dikombinasikan dengan menahan napas, yang dikenal sebagai control pause dan extended pause (Bruton, Lewith, 2005: 42).

Latihan pernapasan buteyko tidak bertentangan dengan manajemen asma secara konvensional. Latihan pernapasan buteyko menjadi pelengkap manajemen asma. Awalnya, manfaat latihan pernapasan buteyko yaitu terlihat pada pengurangan gejala dan pengurangan penggunaan bronkodilator (Alan Ruth, 2014: 16). Menurut Rosalba Courtney, DO (2008: 61) latihan pernapasan buteyko bermanfaat meningkatkan rasa kontrol pada penderita asma, sehingga mengurangi kecemasan terhadap gejala asama. Rasa kekurangan CO2 yang komprehensif pada latihan pernapasan buteyko membantu mengurangi gejala dan mengendalikan penyebabnya (misalnya, mengurangi pernapasan dan menahan napas).

Secara garis besar, teknik pernapasan buteyko bertujuan untuk memperbaiki pola napas penderita asma dengan cara memelihara keseimbangan kadar $\mathrm{CO}^{2}$ dan nilai oksigenasi seluler yang pada akhirnya dapat menurunkan gejala asma. Metode buteyko digunakan terutama sebagai teknik alami untuk mengurangi gejala dan keparahan asma. Hal ini juga digunakan oleh penderita asma untuk mengurangi ketergantungan pada obat-obatan. Metode ini juga digunakan untuk kondisi pernapasan lainnya termasuk bronkitis dan emfisema (Dupler, 2005).

Latihan pernapasan buteyko yang penulis gunakan merupakan program latihan yang disusun oleh Buteyko Breathing Asossiation (www.buteykobreathing.org). Sebelum melakukan teknik pernapasan buteyko, beberapa hal yang harus diperhatikan yaitu: (1) pemilihan tempat yang tepat, karena buteyko memerlukan konsentrasi yang baik, (2) dilakukan secara rutin dan teratur, (3) menentukan tujuan yang ingin dicapai. Latihan pernapasan buteyko dilaksanakan 3 kali sehari (pagi, siang, dan malam) selama 4 minggu. Latihan pernapasan buteyko dilakukan sebelum makan, kemudian selama latihan pernapasan yang digunakan yaitu bernapas menggunakan hidung. 


\section{Arus Puncak Ekspirasi (APE)}

Arus puncak ekspirasi (APE) adalah aliran maksimum dicapai selama ekspirasi dilakukan dengan kekuatan maksimal mulai tingkat inflasi paru maksimal (Quanjer, 1997: 3). APE adalah besarnya aliran udara maksimum yang dicapai saat ekspirasi dengan usaha paksa secara maksimal dari kapasitias paru total (Rudi Dermawan, dkk, 2013: 210). Faktor-faktor yang menentukan APE adalah sebagai berikut:

a. Dimensi saluran udara intra dan extrathoracic besar. Panjang dan kaliber saluran udara intrathoracic meningkat dengan volume paru-paru selama pertumbuhan; dalam individu, kaliber adalah fungsi dari tekanan transbronchial, dan karenanya, volume dan sifat elastis paru-paru, dan kepatuhan saluran udara. Kedua diameter saluran napas dada dan kepatuhan dipengaruhi oleh fleksi dan ekstensi leher

b. Gaya yang dihasilkan oleh otot-otot ekspirasi, terutama perut.

c. Cepatnya tekanan alveolar maksimal tercapai, yang bergantung pada sifat kekuatankecepatan otot ekspirasi.

Situasi patologis yang merusak APE, sejauh ini yang paling umum adalah dari gangguan struktur atau fungsi dari saluran udara intrathoracic. APE juga dapat terganggu oleh obstruksi di saluran udara extrathoracic; kondisi yang membatasi ekspansi dada atau yang memengaruhi fungsi otot pernapasan; dan dengan integritas sistem saraf. Dalam proses ketat karena penyakit paru-paru interstitial, efek dari kerugian di volume paru-paru pada PEF dapat diimbangi oleh peningkatan paru elastisitas (Quanjer, 1997: 3). Seseorang dikatakan masih dalam batas skala normal, jika nilai APE-nya antara 80 \%-120 \% dari nilai yang seharusnya, pada penderita asma nilai APE-nya $<80 \%$ (Yunus, 2003). Pada penelitian ini peneliti menggunakan pengukuran APE sesaat, pengukurannya dilaksanakan pada saat pretest, minggu pertama, kedua, ketiga, dan posttest.

\section{Peak Flow Meter}

Sebuah peak flow meter adalah alat genggam kecil yang mengukur seberapa cepat seseorang bisa meniup udara keluar dari paru-paru dengan sekuat-kuatnya, setelah menghirup maksimal. Pengukuran ini disebut arus puncak ekspirasi (APE). Peak flow meter membantu dalam menilai aliran udara melalui saluran udara dan dengan demikian membantu untuk menentukan derajat obstruksi pada paru-paru. Pengukuran APE dipelopori oleh Wright yang memroduksi pengukur pertama yang khusus dirancang untuk mengukur indeks ini pada fungsi paru-paru. Karena desain asli diperkenalkan pada akhir 1950-an, dan perkembangan selanjutnya yang lebih portabel, biaya lebih rendah versi (yang 'Mini-Wright' peakflow meter), desain lainnya dan salinan telah tersedia di seluruh dunia. 
Menurut Quanjer (1997: 2) peak flow meters telah digunakan secara luas untuk memantau pasien dengan penyakit asma. Pengukuran APE adalah nilai dalam mengidentifikasi keterbatasan aliran udara. Pengukuran APE berfungsi untuk mengukur seberapa cepat kemampuan paru-paru meniup udara keluar. APE diukur menggunakan peak flow meter dan membantu mengetahui ketika asma dalam keadaan baik atau tidak terkontrol (Asthma Society of Ireland, 2013: 26).

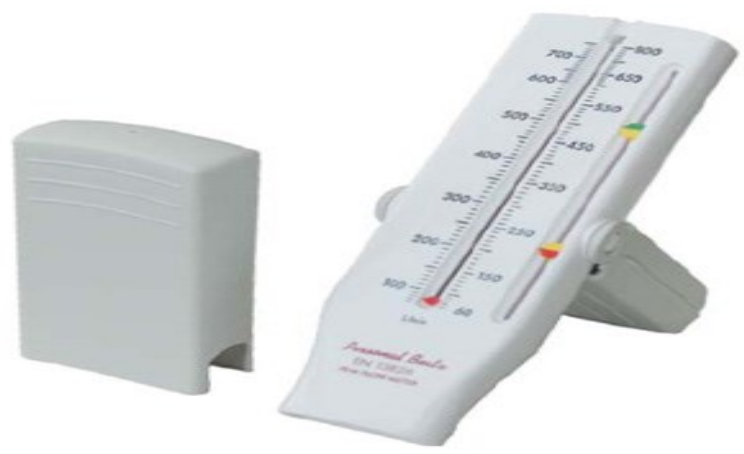

Gambar 9. Peak Flow Meter/Peak Expiratory Flow Rate

Nilai APE yang normal bervariasi sesuai usia, tinggi badan, dan jenis kelamin. Meskipun demikian, skor normal pasien harus berada dalam jarak $20 \%$ dari orang yang sama usia, jenis kelamin, dan tinggi yang tidak memiliki asma (Adeniyi dan Erhabor, 2011: 5). Pengukuran peak flow dapat digunakan untuk menentukan kondisi pasien setelah serangan akut berat. Dips besar dalam pembacaan adalah indikasi bahwa asma mereka belum terkendali, dan mengharuskan untuk melanjutkan terapi. Salah satu ciri asma adalah variasi dalam obstruksi aliran udara. Variasi yang cukup besar dalam APE selama periode singkat dapat direkam dengan mengukur arus puncak dua kali sehari, sebaiknya pagi dan malam hari. Pasien asma sering menunjukkan variasi diurnal dengan pembacaan jatuh tajam di malam hari atau awal pagi, yang disebut 'pagi dips'. Variasi setidaknya $15 \%$ dari maksimum didirikan diasumsikan indikasi asma (Adeniyi dan Erhabor, 2011: 5).

Menurut Adeniyi dan Erhabor, (2011: 5) cara melakukan pengukuran APE menggunakan peak flow meter yaitu:

a. Atur kursor ke posisi nol. Catatan, jangan sentuh kursor saat mengeluarkan napas.

b. Berdiri dan memegang puncak flow meter secara horizontal di depan mulut.

c. Ambil napas dalam-dalam, kemudian tutup bibir di sekitar mouth piece pada flow meter, pastikan tidak ada kebocoran udara di sekitar bibir.

d. Hembuskan napas sekuat dan secepat mungkin.

e. Perhatikan jumlah ditunjukkan oleh kursor. 
f. Kembali kursor ke nol dan ulangi urutan ini dua kali lebih, sehingga mendapatkan tiga bacaan.

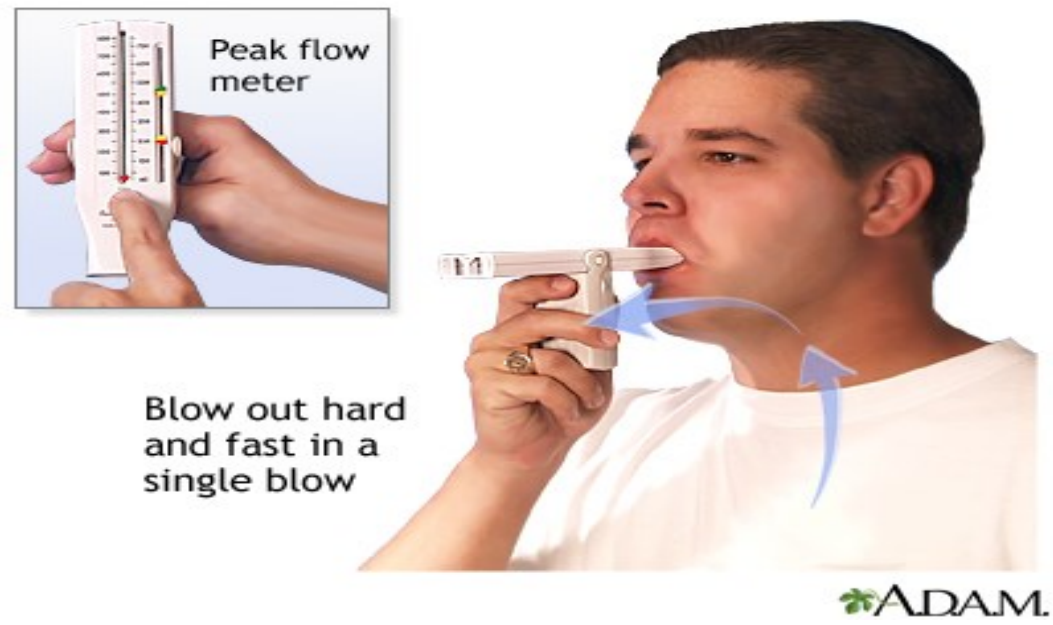

Gambar 10. Cara Menggunakan Peak Flow Meter

Dalam setiap pemeriksaan APE sebaiknya dilakukan tiga kali tiupan, kemudian diambil angka tertinggi. Tiupan dilakukan setelah inspirasi dalam, dilanjutkan tiupan dengan cepat dan kuat (Pradjnaparamita, 1997). Nilai yang dianggap reprodusibel ialah jika perbedaan antara 2 nilai yang didapat $<10 \%$ untuk 3 kali manuver atau $<15 \%$ untuk 4 kali manuver dihitung dari nilai APE tertinggi (Alsagaff dan Mangunegoro, 1993 dalam Allivia Firdahana 2010: 19). Pembacaan tertinggi atau terbaik dari semua tiga pengukuran adalah aliran puncak pada waktu itu. Pembacaan tertinggi harus dicatat dalam buku harian asma harian pasien atau direkam pada grafik peak flow. Untuk memastikan hasil peak flow meter sebanding, pasien disarankan untuk menggunakan meter dengan cara yang sama setiap waktu dan pada waktu yang sama setiap hari.

\section{METODE PENELITIAN}

Desain dalam penelitian ini menggunakan metode penelitian kuantitatif, yang menurut Sugiyono (2013: 7) dikatakan metode kuantitatif karena data penelitian berupa angka-angka dan analisis menggunakan statistik. Penelitian ini dilaksanakan di Laboratorium Olahraga Terapi dan Rehabilitasi FIK Universitas Negeri Yogyakarta, selama empat minggu pada bulan Mei-Juni 2016. Populasi pada penelitian ini adalah mahasiswa UNY yang menderita asma. Berdasarkan data dari Klinik Kesehatan UNY terdapat empat puluh kasus asma yang tercatat selama tahun 2015. Kemudian setelah menggunakan rumus sample size lemeshow didapat jumlah minimal sampel yaitu berjumlah dua belas orang. 
Penelitian ini merupakan penelitian pre-eksperimen design dengan menggunakan tes awal dan tes akhir (the one group, pretest-posttest design) (Sugiyono, 2013: 74). Perlakuan yang dilakukan selama 4 minggu dengan frekuensi 3 kali sehari (pagi, siang, dan malam). Data hasil test diambil pre-tes dan post test. Desain penelitian digambarkan sebagai berikut:

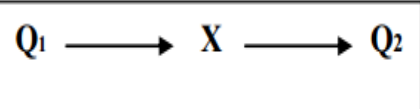

\section{Gambar 3. Desain Penelitian Eksperimen Semu}

Keterangan:

Q1: Tes awal (pretest).

$\mathrm{X}$ : Perlakuan yang diberikan yaitu latihan pernapasan buteyko selama empat minggu.

Q2: Tes akhir (posttest).

\section{Instrumen dan Teknik Pengumpulan Data}

Intrumen penelitian adalah alat atau fasilitas yang digunakan peneliti di dalam pengumpulan data agar pekerjaannya lebih mudah dan hasilnya lebih baik dalam arti lebih cermat, lengkap, dan sistematis sehingga lebih mudah diolah (Suharsimi Arikunto, 2005: 160). Instrumen pengumpulan data dapat berupa alat evaluasi. Secara garis besar alat evaluasi digolongkan menjadi dua macam yaitu tes dan nontes. Untuk itu dalam penelitian ini instrumen yang digunakan adalah instrumen tes. Instrumen pengumpulan data pada penelitian ini berupa tes APE dengan satuan liter/menit dan asthma control test.

Teknik pengumpulan data pada penelitian ini adalah dengan cara objektif menggunakan peak flow meter test dilakukan setiap minggu hingga minggu keempat dan dengan cara subjektif menggunakan kuesioner pada pretest dan posttest minggu keempat.

\section{HASIL PENELITIAN}

\section{Deskripsi Hasil Kemajuan Kondisi Asma Selama Perlakuan}

Kemajuan kondisi asma pada penelitian ini dapat dilihat dari data hasil tes APE yang diukur dengan peak flow meter (PFM) setiap minggu selama empat minggu seperti yang dijelaskan pada Tabel 1. 
Tabel 1. Data Hasil Tes Arus APE dengan PFM Selama Empat Minggu

\begin{tabular}{|c|c|c|c|c|c|}
\hline $\begin{array}{c}\text { No. } \\
\text { Subjek }\end{array}$ & Pretest & Posttest 1 & Posttest 2 & Posttest 3 & Posttest 4 \\
\hline 1 & 320 & 340 & 350 & 370 & 380 \\
\hline 2 & 280 & 400 & 430 & 450 & 470 \\
\hline 3 & 410 & 430 & 450 & 470 & 490 \\
\hline 4 & 350 & 360 & 380 & 400 & 410 \\
\hline 5 & 260 & 270 & 290 & 310 & 330 \\
\hline 6 & 270 & 290 & 290 & 310 & 320 \\
\hline 7 & 360 & 390 & 430 & 450 & 480 \\
\hline 8 & 390 & 400 & 420 & 440 & 460 \\
\hline 9 & 280 & 300 & 320 & 350 & 390 \\
\hline 10 & 380 & 400 & 430 & 440 & 460 \\
\hline 11 & 290 & 320 & 340 & 370 & 390 \\
\hline 12 & 300 & 320 & 350 & 370 & 380 \\
\hline
\end{tabular}

Distribusi skor APEsubjek pada pretest memiliki skor rata-rata sebesar 324.17 dan skor terendah sebesar 260 serta skor tertinggi 410. Pada minggu ke-1 memiliki skor rata-rata sebesar 351.67 dan skor terendah sebesar 270 serta skor tertinggi 430. Pada minggu ke-2 memiliki skor rata-rata sebesar 373.33 dan skor terendah sebesar 290 serta skor tertinggi 450 . Pada minggu ke-3 memiliki skor rata-rata sebesar 394.17 dan skor terendah sebesar 310 serta skor tertinggi 470. Pada posttest memiliki skor rata-rata sebesar 413.33 dan skor terendah sebesar 320 serta skor tertinggi 490.

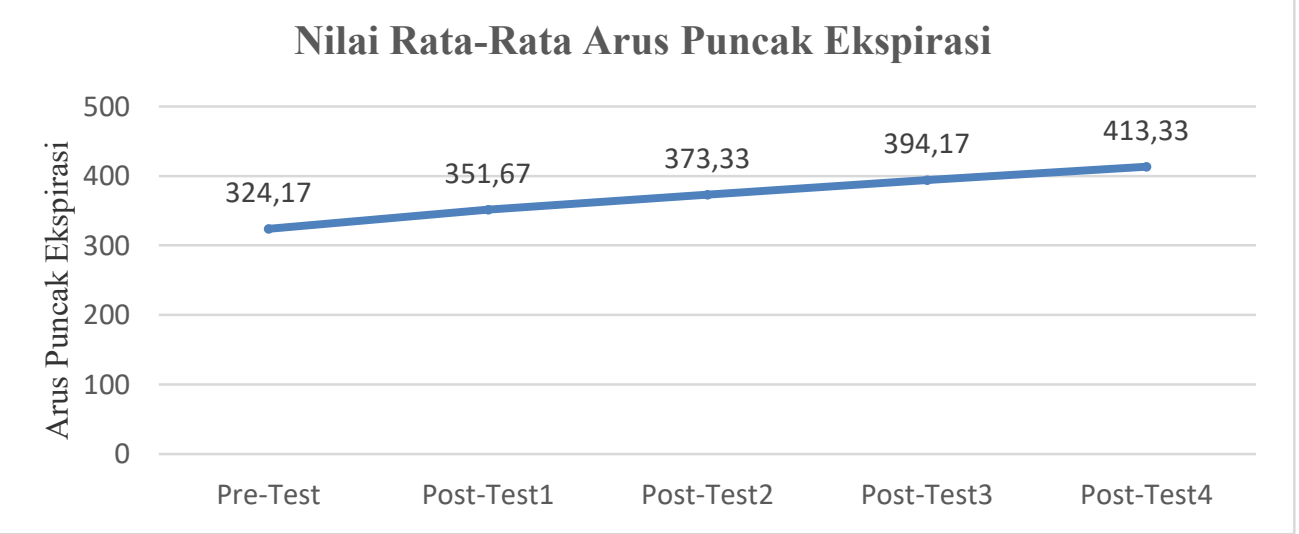

Gambar 4. Diagram Garis Rata-Rata Hasil Tes APE

Berdasarkan Gambar 4 dapat dilihat bahwa terdapat kenaikan nilai APE subjek setiap minggu. Hal ini berarti latihan pernapasan buteyko berpengaruh terhadap peningkatan nilai APE. 


\section{Hasil Tes APE Berdasarkan Pelangi Asma}

Tabel 2. Data Hasil Test APE Berdasarkan Pelangi Asma

\begin{tabular}{|c|c|c|c|c|c|}
\hline Katagori & Pretest & Posttest 1 & Posttest 2 & Posttest 3 & Posttest 4 \\
\hline M & $25 \%$ & $0 \%$ & $0 \%$ & $0 \%$ & $0 \%$ \\
\hline K & $58 \%$ & $75 \%$ & $58 \%$ & $58 \%$ & $25 \%$ \\
\hline H & $17 \%$ & $25 \%$ & $42 \%$ & $42 \%$ & $75 \%$ \\
\hline Jumlah & $100 \%$ & $100 \%$ & $100 \%$ & $100 \%$ & $100 \%$ \\
\hline
\end{tabular}

Berdasarkan Tabel 2 pada pretest terdapat kategori merah $25 \%$, kategori kuning $58 \%$, dan kategori hijau $17 \%$. Kemudian pada posttest 4, kategori merah $0 \%$, kategori kuning 25 $\%$, dan kategori hijau $75 \%$. Berdasarkan hasil tersebut dapat diartikan bahwa latihan pernapasan buteyko meningkatkan penilaian pelangi asma.

\section{Hasil Kemajuan Kondisi Asma dengan Asthma Control Test}

Hasil kemajuan kondisi asma selain menggunakan tes APE juga menggunakan asthma control test berupa kuesioner yang dilaksanakan saat pretest dan posttest.

Tabel 3. Data Skor Hasil Asthma Control Test

\begin{tabular}{|c|c|c|}
\hline No. Subjek & Pretest & Posttest \\
\hline 1 & 18 & 22 \\
\hline 2 & 21 & 23 \\
\hline 3 & 12 & 19 \\
\hline 4 & 14 & 19 \\
\hline 5 & 18 & 21 \\
\hline 6 & 18 & 23 \\
\hline 7 & 21 & 23 \\
\hline 8 & 18 & 21 \\
\hline 9 & 19 & 23 \\
\hline 10 & 21 & 23 \\
\hline 11 & 15 & 21 \\
\hline 12 & 17 & 21 \\
\hline
\end{tabular}

Berdasarkan Tabel 3 data skor Asthma Control Test pada post-test terdapat peningkatan setelah dilakukan perlakuan selama empat minggu.

\section{PEMBAHASAN}

Teknik pernapasan buteyko memiliki kegunaan untuk memperbaiki cara bernapas pada penderita asma agar dapat bernapas secara efisien dan benar agar gejala asma seperti hiperventilasi dapat dikurangi (Kolb, 2009). Penderita asma pada penelitian ini belajar 
bernapas dengan hidung dan menggunakan pernapasan diafragma dalam kegiatan sehariharinya. Jenis pernapasan yang dilakukan selama latihan teknik pernapasan buteyko adalah pernapasan diafragma yakni otot diafragma dilatih untuk bernapas dan menahan napas menurut kemampuan penderita asma (Roy, 2006).

Latihan pernapasan buteyko dikembangkan dari Rusia oleh Buteyko yang mengajarkan untuk mengurangi pernapasan (breath less). Tujuan utamanya adalah menurunkan ventilasi total (minute volume) selama sesi latihan, mengembalikan pusat kontrol respirasi dan mengontrol jalan napas dalam masa yang lebih panjang. Tujuan lain yang lebih penting adalah mendorong pernapasan hidung daripada pernapasan mulut dan teknik untuk membersihkan hidung diajarkan untuk menunjang hal itu (Motin, 1999 dalam Thomas, 2004).

Dari hasil pengambilan data pretest rata-rata nilai APE subjek penelitian yaitu sebesar 324.17 1/menit. Berdasarkan tabel nilai normal APE rata-rata hasil pretest tersebut berada di bawah batas normal, hal ini dapat berarti terdapat masalah pada sistem pernapasan dalam kasus ini yaitu penyakit asma.

Setelah latihan selama 4 minggu, didapat data nilai posttest pada subjek, nilai rata-rata APE posttest yaitu 413,33 Liter/menit. Berdasarkan tabel nilai normal APE nilai tersebut masih berada di bawah batas normal, tetapi jika dibandingkan dengan nilai pretes, nilai posttest mengalami kenaikan yaitu sebesar 89,17 1/menit. Berdasarkan hasil ini berarti adanya pengaruh latihan pernapasan buteyko selama empat minggu terhadap peningkatan nilai APE.

\section{KESIMPULAN}

Berdasarkan hasil penelitian dan pembahasan yang telah dibahas pada bab sebelumnya tentang pengaruh latihan pernapasan buteyko terhadap APE penderita asma mahasiswa Universitas Negeri Yogyakarta, dapat diambil kesimpulan sebagai berikut: latihan pernapasan buteyko meningkatkan APE secara signifikan pada penderita asma mahasiswa Universitas Negeri Yogyakarta. Peningkatan secara signifikan dimulai sejak posttest minggu pertama. Dari penelitian ini diharapkan, praktisi kesehatan dapat membuat program rehabilitasi dan promosi latihan pernapasan buteyko pada penderita asma, latihan pernapasan buteyko dapat dijadikan pilihan managemen asma pada penderita asma. Evaluasi dan monitoring tersebut sangat penting untuk melihat pengaruh latihan pernapasan buteyko.

\section{DAFTAR PUSTAKA}

Austin, G. (2013). Buteyko technique use to control asthma symptoms. Nursing Times; 109 (16) 16-17. 
Ekowati Rahajeng. (2012). Upaya Pengendalian Penyakit Tidak Menular Di Indonesia. Menular. Jakarta: Kementrian Kesehatan RI. Diakses dari: http://www.depkes.go.id/download.php?file=download/pusdatin/buletin/buletinptm.pdf. Pada 14 Maret 2015 |12:40 WIB

Fadhil. (2009). Teknik Pengolahan Nafas. Diakses pada tanggal 5 November 2015 dari http://www.wikipedia.com/teknik_pengolahan_nafas.html.

Gordon, F. (2002). Gangguan Pernapasan: Panduan Latihan Lengkap. Cetakan Kedua. (Diterjemahkan oleh: Agusta Wibawa). Jakarta: PT Raja Grafindo Persada.

Gregg Ian \& A. J. Nunn. (1973). "Peak Expiratory Flow in Normal Subjects.” British Medical Journal, 3, 282-284.

Irman Somantri. (20070. Asuhan Keperawatan pada Pasien dengan Gangguan Sistem Pernapasan. Jakarta: Salemba Medika.

Kolb, P. (2009). Buteyko for the Reversal of Chronic Hyperventilation. Diakses pada tanggal 7 November 2015 || 19.00 WIB, dari http://knol.google.com/k/alex-spence/buteyko.

Persatuan Dokter Paru Indonesia. (2003). Asma: Pedoman diagnosis dan Penatalaksanaan di Indonesia. Jakarta: PDPI. Sumber: http://www.klikpdpi. com/ konsensus/asma/asma .html. Diakses pada 26 Desember 2015 || 13.21 WIB.

Pusat Data dan Informasi Kementerian Kesehatan RI. (2014). You can Control Your Atshma. InfoDATIN. Jakarta: Kementerian Kesehatan RI.

Rosalba Courtney, DO. (2008). Strengths, Weaknesses, and Possibilities of the Buteyko Breathing Method. Biofeedback. Volume 36, Issue 2, pp. 59-63. Sumber: https://www.resourcenter.net/images/AAPB/Files/Biofeedback/2008/biof_summer_b uteyko_breathing.pdf. Diakses pada 2 september 2016 || 10.00 WIB.

Rudi Dermawan, dkk. (2013). Uji Diagnostik Rasio Tetap Terhadap Batas Bawah Normal VEP/KVP1 untuk Menilai Obstruksi Saluran Napas. Jakarta: Jurnal Respirologi Indonesia Vol. 33, No. 4. Sumber: http://jurnalrespirologi.org/wpcontent/uploads/2013/11/Makalah-1-Dr.-Rudi-ok.pdf. Diakses pada 20 Juni 2016 || $21.05 \mathrm{WIB}$

Sandy Thomas. (2004). Buteyko: A useful tool in the management of asthma. International Journal of Therapy and Rehabilitation, Vol 11, No 10, 476-480.

Sigit Nugroho. (2009). Terapi Pernapasan pada Penderita Asma. Medikora. V. (1). 71-91.

Suharmiati, Lestari Handajani \& Adianti Handajani. (2010). Hubungan Pola Penggunaan Rokok dengan Tingkat Kejadian Penyakit Asma. Surabaya: Pusat Penelitian dan Pengembangan Sistem dan Kebijakan Kesehatan, Litbang Kesehatan, Kementerian Kesehatan Korespondensi. 
Yunus F. (2003). Aplikasi klinik pada volume paru. Makalah disajikan dalam Workshop Faal Paru. 16 Februari 2003. Jakarta. Bagian Pulmonologi dan Kedokteran Respirasi FKUI. 